\title{
AVALIAÇÃO DA PRÁTICA HIGIÊNICO-SANITÁRIA NA ORDENHA NA REGIÃO DE RIO BONITO - RIO DE JANEIRO: UMA ABORDAGEM QUALITATIVA
}

\section{Assessment of hygienic sanitary practice in milking in the region of Rio Bonito - Rio de Janeiro, Brazil: a qualitative approach}

\author{
Edvaldo da Costa Carvalho ${ }^{*}$, Paulo Henrique Pereira de Moraes ${ }^{1}$, \\ Fabiula Ferrarez Silva Gajo ${ }^{1}$, Marcelo Henrique Otenio ${ }^{2}$
}

\begin{abstract}
RESUMO
O presente trabalho buscou investigar o conhecimento de ordenhadores de vaca no manejo sanitário da ordenha e cuidados com a qualidade do leite nas Unidades Produtoras de Leite (UPL) no município de Rio Bonito - RJ, por meio de uma abordagem qualitativa. Para isso, foram realizadas entrevistas com ordenhadores de dez propriedades rurais da cidade de Rio Bonito no Estado do Rio de Janeiro, baseadas em um formulário semi-estruturado, composto de levantamentos observacionais e perguntas cujas respostas foram gravadas, transcritas e analisadas de acordo com a metodologia de triangulação. A análise individual dos discursos mostrou que os ordenhadores apresentavam prévia experiência em ordenha de animais, mas não tinham ideias claras em relação à melhoria do seu fluxo de trabalho. Conclui-se que determinados fatores como a escolaridade e volume de produção não influenciaram na aplicação da prática de higiene de ordenha e que a falta de mão de obra especializada acarreta a falha no controle higiênico-sanitário efetivo.
\end{abstract}

Palavras-chave: indicadores de contaminação; bovino leiteiro; manipuladores; manejo sanitário.

1 Universidade Federal de Juiz de Fora (UFJF), Programa de Mestrado Profissional em Ciência e Tecnologia de Leite e Derivados (Parceria UFJF/EMBRAPA/EPAMIG), Juiz de Fora, MG, Brasil. Rua Itaporanga, lote 29, quadra 144, Vista Alegre, São Gonçalo, 24724-070, Rio de Janeiro, RJ, Brasil. E-mail: edvaldogol@yahoo.com.br

2 Empresa Brasileira de Pesquisa Agropecuária (EMBRAPA), Centro Nacional de Pesquisa de Gado de Leite, Juiz de Fora, MG, Brasil.

* Autor para correspondência. 


\begin{abstract}
The present study sought to investigate the knowledge of cow milkers on sanitary management of milking and caring for the quality of milk in the Milkproducing Units in the region of Rio Bonito-RJ, Brazil, through a qualitative approach. In order to achieve this objective, we interviewed ten milkers from farms in the Rio Bonito city, state of Rio de Janeiro, using a semi-structured form, consisting of observations and questions whose responses were recorded, transcribed and analyzed according to the triangulation methodology. Individual analysis of discourses showed that milkers had previous experience milking of animals, but they had no clear ideas on how to improve their workflow. It can be concluded that certain factors like scholarity and production volumes did not influence the application of hygienic sanitary practice and lack of skilled labor leads to failure in effective hygienic sanitary control.
\end{abstract}

Keywords: contamination indicators; dairy cattle; food handlers; sanitary management.

\section{INTRODUÇÃO}

A evolução da economia e do mercado causou modificações importantes na cadeia agroindustrial do leite, que resultaram principalmente em mais investimento no setor e na capacitação de funcionários para atividade de manipulação de alimentos. Com isso, o controle higiênico sanitário das matérias-primas desde as suas origens tornou-se um aspecto fundamental, que impactou tanto a indústria quanto os produtos processados (VISOTTO et al., 2011).

Paralelamente, a necessidade de uma dieta adequada, de uma melhor qualidade de vida e a busca por alimentos saudáveis levaram a um aumento no consumo de leite e produtos lácteos, como queijo e iogurte. Como o leite é um alimento de pronto consumo e indicado para idosos, gestantes e convalescentes, inclusive em dietas hospitalares, a sua inocuidade é de suma importância para que este não cause riscos à saúde do consumidor (SILVA, 2010). Nessa busca pela qualidade, o setor agropecuário leiteiro discute exaustivamente tais questões. Diante disso elaborou, publicou e implementou a instrução normativa 51/2002 (BRASIL, 2002), do Ministério da Agricultura, Pecuária e Abastecimento (MAPA), composta por regulamentos técnicos sobre produção, identidade e qualidade dos diversos tipos de leite no país, bem como a coleta e o transporte a granel do leite cru refrigerado, que foi alterada pela Instrução Normativa 62/2011 (BRASIL, 2011).

O termo qualidade do leite ganhou contornos diferentes e abrange não apenas as características nutricionais do produto como também as características de seu processo produtivo, quanto à higiene na ordenha, refrigeração e manutenção do leite em temperaturas de $4{ }^{\circ} \mathrm{C}$, que garantem a qualidade global do alimento (Rangel et al., 2009; Galvão Júnior et al., 2010).

Ataíde et al. (2008) relatam que, devido à sua riqueza em nutrientes, o leite é susceptível ao desenvolvimento de um grande número de microrganismos provenientes do próprio animal, do ambiente, do homem e dos utensílios usados na ordenha.

Devido a esses fatores surge a preocupação de técnicos e autoridades da área de saúde em manter o produto com alta qualidade e livre de microrganismos. O leite deve ser pasteurizado corretamente, para evitar o risco de veiculação de microrganismos relacionados com doenças (SILVA, 2008).

Condições de resfriamento também interferem na qualidade microbiológica, porém, mesmo sob refrigeração, o leite 
pode servir como meio para a proliferação microbiana e ser deteriorado, já que algumas bactérias conseguem se multiplicar a cada 20 ou 30 minutos (GUERREIRO et al., 2005).

Quanto aos equipamentos de ordenha, Araújo (2009) destacou as teteiras da ordenhadeira mecânica como a maior causa de contaminação entre as vacas. Entretanto, o adequado manejo pré-ordenha com uma adequada higienização pode reduzir a contaminação dos tetos não só por bactérias ambientais como também por bactérias provenientes de outros animais.

Neste contexto, diante da expressiva produção de leite na região, o presente estudo buscou investigar o conhecimento de ordenadores de vaca no manejo sanitário da ordenha e cuidados com a qualidade do leite nas Unidades Produtoras de leite (UPL) no município de Rio Bonito - RJ, por meio de uma abordagem qualitativa.

\section{MATERIAL E MÉTODOS}

O estudo abrangeu pesquisa bibliográfica e estudo de caso microrregional. Foram visitadas no mês de abril de 2013 dez propriedades produtoras de leite da região de Rio Bonito no estado do Rio de Janeiro, nove delas com ordenha manual e uma com ordenha mecânica. O tamanho da amostra foi definido a partir do número de criadores de bovinos cadastrados pelo Serviço Oficial de Defesa Agropecuária do município, o qual possui 239 criadores registrados. Deste total, cerca de $40 \%$ representado por 96 criadores são produtores de leite. Esses dados foram obtidos na Federação da Agricultura, Pecuária e Pesca do Rio de Janeiro - FAERJ.

Devido à ausência de grandes laticínios ou cooperativas de produtores que captam leite na região, há uma menor preocupação com a qualidade do leite produzido pelos pecuaristas. A escolha do município para a pesquisa foi pelo caráter representativo deste recorte no universo de produtores, após a constatação de que a produção de leite da região está restrita a pequenas propriedades rurais e reduzida produção diária de leite.

As propriedades foram visitadas e os produtores convidados a participar. Aqueles que concordaram, assinaram o termo de consentimento livre e esclarecido. Os produtores foram entrevistados individualmente, por meio de gravador digital, com aplicação de um questionário adaptado de Gomes (2007) e Zoccal et al. (2008). Foram realizadas as seguintes perguntas: Produtor? Idade? Escolaridade? Como aprendeu o ofício? Tem algum treinamento? Como foi esse treinamento? Qual a sua produção de leite diária? Qual o destino do leite obtido na propriedade? Explique como você faz para ordenhar as vacas, desde o começo? Você considera que o leite de vaca possa transmitir algumas doenças. O que você sabe sobre isso? Existe alguma coisa que você acha que poderia mudar aqui para melhorar seu trabalho? Fala-me sobre isso!

Após esta etapa foram realizadas as observações dos aspectos do manejo sanitário na ordenha e pós-ordenha baseado na descrição de Quivy; Campenhoudt (2003), que busca entender como são realizados os procedimentos e as condições de risco para contaminação do produto. Nessa etapa foram observados os seguintes aspectos: Aspecto do ambiente e sua rotina de limpeza; Equipamentos utilizados na ordenha e limpeza e/ou higienização dos mesmos; Fonte de água e tratamento (uso de cloro) da água da sala de ordenha; Procedimento de limpeza dos tetos; Secagem do teto após lavagem e aplicação do pré e pós-dipping; Testagem do leite no primeiro jato; Procedimento de higiene pessoal antes e depois da ordenha; Aspecto e rotina de limpeza do equipamento (balde ou ordenhadeira); Forma de armazenamento do leite ordenhado até seu recolhimento/utilização; Tempo de permanência do leite em temperatura ambiente.

O procedimento de abordagem, entrevista e observação de manejo e práticas foi 
idêntico para todos os entrevistados. Somente depois de coletados os dados necessários para esta pesquisa é que o pesquisador se dispôs em atender alguma demanda técnica ou dúvida do produtor sobre seus procedimentos. Em cada propriedade, a sequência dos procedimentos de ordenha foi observada cuidadosamente, levando-se em consideração os itens previstos na planilha de avaliação de boas práticas, baseado principalmente nas legislações IN 51 (BRASIL, 2002) e IN 62 (BRASIL, 2011).

Os resultados da observação dos aspectos de manejo sanitário da ordenha e pósordenha foram submetidos à análise estatística do tipo descritiva, tabulados em planilhas eletrônicas do tipo Microsoft Excel ${ }^{\circledR} 2007$ (Microsoft Corporation, USA). Os resultados foram expressos na forma de tabelas.

Os dados coletados nas entrevistas gravadas foram transcritos em Microsoft Word $^{\circledR} 2007$ (Microsoft Corporation, USA) e trabalhados pela técnica da Triangulação para análise qualitativa das narrativas orais. A triangulação consiste numa estratégia de pesquisa que se apoia em métodos científicos testados e consagrados. Essa técnica serve e adequa-se a determinadas realidades, com fundamentos interdisciplinares como uma forma de aumentar a validade ou para reforçar a credibilidade de resultados da investigação, cruzando os resultados de diferentes abordagens (MINAYO et al., 2010). As respostas obtidas foram categorizadas e submetidas à análise estatística do tipo descritiva.

\section{RESULTADOS E DISCUSSÃO}

\section{Aspectos observacionais}

A observação dos aspectos do manejo sanitário na ordenha e pós-ordenha, conforme mostra a Figura 1, buscou entender como são realizados os procedimentos e as condições de risco para contaminação dos produtos. Constatou-se que em $70 \%$ das observações a limpeza do ambiente era realizada adequadamente e que em $100 \%$ dos casos, utilizava-se detergente na higienização dos utensílios utilizados na ordenha. Esses mesmos 100\% utilizavam balde, latão e

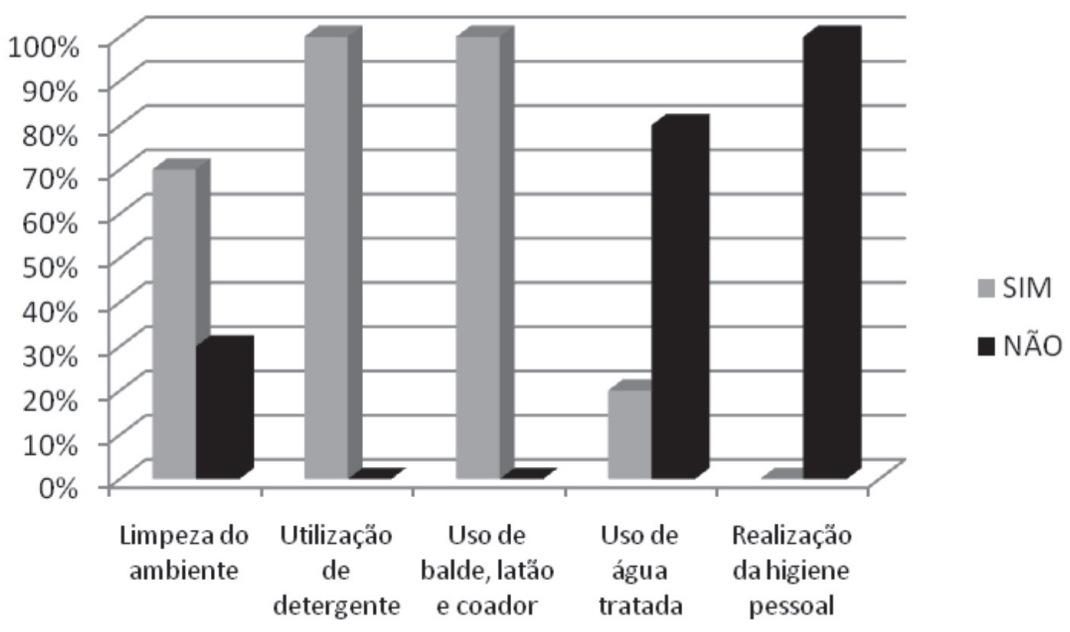

Figura 1 - Aspecto do manejo sanitário na ordenha e pós-ordenha 
coador na ordenha. Do total dos produtores entrevistados, 20\% utilizavam água corrente clorada na origem, enquanto os outros $80 \%$ utilizavam água de poço sem nenhum tipo de tratamento. Em relação à higiene pessoal, 100\% dos produtores não a realizam adequadamente.

A higienização adequada dos tetos foi identificada em $10 \%$ dos casos analisados, $40 \%$ utilizavam apenas água e os outros 50\% não realizavam nenhum tipo de higienização. Quanto à secagem dos tetos, 20\% das propriedades a realizavam com uso de papel toalha, $30 \%$ utilizavam panos comuns para enxugar os tetos de todos os animais e os outros $50 \%$ não enxugavam os tetos antes de iniciar a ordenha. Realizar a secagem completa dos tetos após o pré-dipping com papel toalha descartável é importante devido ao risco de contaminação do leite pelo uso de sanitizantes. Das UPL, 10\% realizavam uso da prática do pré-dipping e 10\% realizavam apenas o pós-dipping; o restante não realizava nenhum dos dois procedimentos, conforme mostra a Figura 2.

Também foi observado que nenhuma das propriedades realizava o uso do teste da caneca para verificação de alterações no leite provenientes de alguma infecção intramamária. Verificou-se também que, após a ordenha, $60 \%$ dos ordenhadores realizavam a higiene dos equipamentos como rotina e adequadamente, e apenas $40 \%$ acondicionava o leite em resfriadores, conforme demostrado na Figura 3.

Resultados semelhantes foram encontrados por Mororó et al. (2010) quando investigou o manejo sanitário da ordenha e qualidade do leite caprino no município de Monteiro (PB). Mororó et al. verificaram que a higienização das instalações e equipamentos ocorreu em $60,9 \%$ dos casos e do total dos entrevistados, $17,4 \%$ não realizam nenhum tipo de higiene nos tetos dos animais. O uso de papel toalha para enxugar os tetos ocorreu em $8,7 \%$ das propriedades, sendo que, $65,2 \%$ usavam panos comuns para todos os animais e $26,1 \%$ não enxugavam. Em $21,7 \%$ das propriedades foi verificado o uso do exame de CMT (Califórnia Mastite Teste) e em $34,8 \%$ era realizado o teste da caneca telada. O pré-dipping não foi constatado em nenhuma das propriedades e o pós-dipping ocorreu em apenas $8,7 \%$ dos casos. Silva et al. (2009) estudaram as características

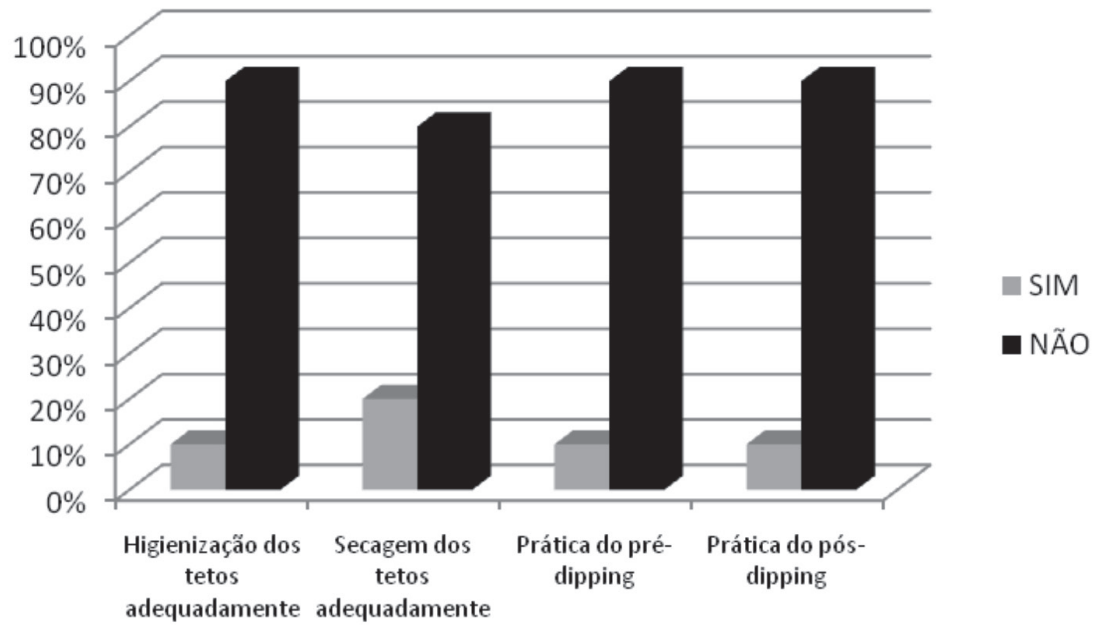

Figura 2 - Condições higiênico-sanitárias dos tetos durante a ordenha 
de produção de leite cru obtido por ordenha manual em propriedades rurais localizadas no município de São Mateus. Observaram que as instalações eram bastantes precárias, o que caracterizava um ambiente não favorável à realização da ordenha. Também observaram que, a maioria dos ordenhadores não adotava hábitos saudáveis de higiene e não realizava exames periódicos de saúde. Alguns cuidados higiênicos com os animais também não eram adotados, reproduzindo um quadro de hábitos culturais enraizados. A ordenha era realizada muito cedo, o que aumenta o tempo de espera entre a ordenha e a entrega dos latões para refrigeração do leite nos tanques, favorecendo a multiplicação de bactérias deteriorantes. A limpeza e sanitização dos equipamentos e utensílios foram pontos críticos, bem como a qualidade duvidosa da água utilizada e a periodicidade do controle sanitário do rebanho, que não era feito adequadamente.

\section{Entrevistas individuais}

Nos resultados da entrevista, para a primeira questão, observou-se que a idade variou entre 29 a 74 anos, com média de 50 anos de idade. Na segunda questão, $50 \%$ dos entrevistados relataram ter até o quinto ano do ensino fundamental, $20 \%$ estavam entre o sexto e o nono ano, $20 \%$ com o ensino médio completo e apenas $10 \%$ com nível técnico concluído.

Quando questionada a aprendizagem do ofício, terceira questão, 90\% relataram ter aprendido com orientações e observações de pessoas próximas com a mesma função, com um grande destaque para a participação dos pais. Apenas 10\% tiveram aprendizagem em instituição especializada na área. Após o aprendizado do ofício, quarta questão, 80\% relataram nunca terem passado por treinamento.

A quinta questão indicou que a produção diária variava de 40 a 200 litros de leite, sendo a mediana de 70 litros. $\mathrm{Na}$ sexta questão observou-se que $20 \%$ dos entrevistados destinavam a produção diária para estabelecimentos registrados e $80 \%$ para os estabelecimentos não registrados. Entre os que enviavam o leite para estabelecimentos não registrados, 50\% também beneficiavam a própria produção, transformando o leite obtido em queijos e outros derivados.

Ainda, perguntando sobre como realizavam a ordenha, $50 \%$ dos entrevistados

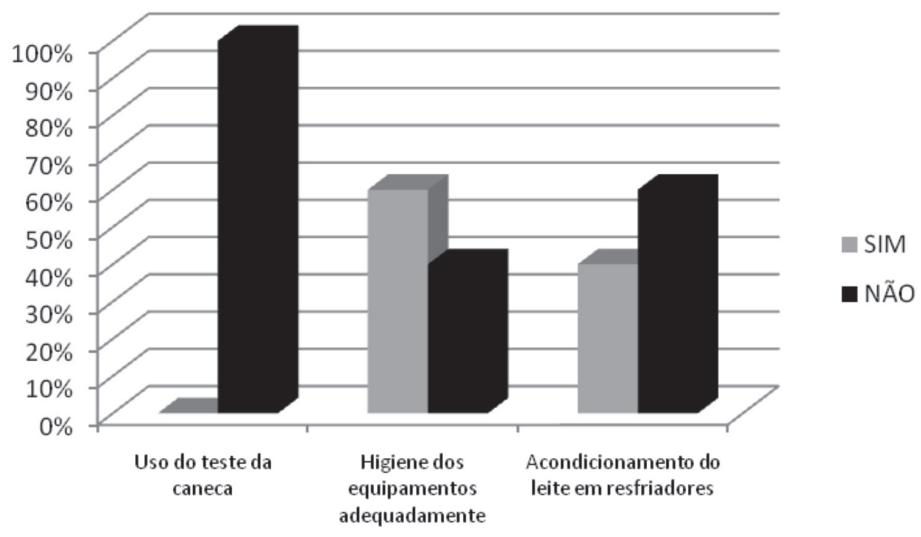

Figura 3 - Uso do teste da caneca, higienização dos equipamentos e acondicionamento correto do leite 
relataram que realizavam a ordenha de forma higiênica, enquanto os outros 50\% demonstraram não ter cuidado algum nessa etapa. Dentre os que relataram realizar a ordenha corretamente, apenas $10 \%$ atendiam as normas necessárias no momento da análise observacional. Na penúltima questão concluímos que $50 \%$ dos entrevistados tinham o conhecimento básico sobre a transmissão de doenças através do leite contaminado, $40 \%$ já ouviram falar, mas alegaram que nunca viram e $10 \%$ demonstraram não ter nenhum tipo de conhecimento a respeito.

Através do último questionamento observamos que $60 \%$ dos entrevistados relataram a necessidade de melhoria relacionada à mão de obra em seu ambiente de trabalho, 20\% apontaram a preocupação com a qualidade do seu serviço e a carência de assistência técnica, 10\% consideraram satisfatória a condição atual e os outros $10 \%$ demonstraram desmotivação para qualquer tipo de melhoria.

Podemos comparar os resultados com os encontrados por Tavoloro et al. (2006) que através da análise global das ideias centrais, obtidas nas entrevistas com os ordenhadores das três propriedades de estudo, demonstraram que os funcionários tinham noção da necessidade de limpeza na ordenha, mas ignoravam a existência da necessidade de uma etapa de desinfecção. Um segundo ponto observado por este mesmo autor é o fato da mão-de-obra ser constituída de apenas um funcionário, ou de um pequeno grupo familiar, que se dedicava a todas as atividades da propriedade, resultado também observado nesta pesquisa. Isso pode contribuir para falhas nos procedimentos higiênico-sanitários da ordenha.

Guerreiro et al. (2005) após a aplicação de um questionário em sua pesquisa, constataram que em todas as propriedades havia falhas nos procedimentos de higiene e limpeza, bem como a ocorrência de muitos animais com mastite sub-clínica, ocorrido por motivo de falhas no controle higiênicosanitário.

\section{CONCLUSÕES}

A partir das evidências obtidas no presente trabalho pode-se afirmar que fatores como escolaridade e idade não influenciaram na aplicação da prática de higiene de ordenha.

Pode-se ainda concluir que, nas propriedades estudadas, há carência de mão de obra especializada, bem como a falta de assistência técnica, levando à falha no controle sanitário efetivo. Além desses fatores, podemos concluir, a partir das respostas obtidas para a questão relacionada às ações que cada entrevistado acreditava ser possível modificar para melhorar a qualidade do seu trabalho, que há uma desmotivação de mais de $50 \%$ dos entrevistados, à qual está associada à baixa remuneração obtida na comercialização do leite.

\section{REFERÊNCIAS}

ARAÚJO, V. M. Monitoramento da qualidade do leite. In: BRITO, A. C.; NOBRE, F. V.; FONSECA, J. R. R. (Org.) Bovinocultura leiteira: Informações técnicas e de gestão. Natal: SEBRAE/ RN, 2009. p. 239-246.

ATAÍDE, W. S. et al. Avaliação microbiológica e físico-química durante o processamento do leite pasteurizado. Revista do Instituto Adolfo Lutz, v. 67 , n. 1, p. 73-77, 2008.

BRASIL. Ministério da Agricultura, Pecuária e Abastecimento. Departamento de Inspeção de Produtos de Origem Animal. Instrução Normativa $\mathrm{n}^{\circ}$ 51, de 18 de setembro de 2002. Aprova os Regulamentos Técnicos de Produção, Identidade e Qualidade do Leite tipo A, do Leite tipo B, do Leite tipo C, do Leite Pasteurizado e do Leite Cru Refrigerado e o Regulamento Técnico da Coleta de Leite Cru Refrigerado e seu Transporte a Granel, em conformidade com os Anexos a esta 
Instrução Normativa. Diário Oficial da República Federativa do Brasil, Brasília, 20 set. 2002. Seção 1, p. 8-13.

BRASIL. Ministério da Agricultura, Pecuária e Abastecimento. Instrução Normativa $\mathrm{n}^{\circ} 62$, de 29 de dezembro de 2011. Aprova o Regulamento Técnico de Produção, Identidade e Qualidade do Leite tipo A, o Regulamento Técnico de Identidade e Qualidade de Leite Cru Refrigerado, o Regulamento Técnico de Identidade e Qualidade de Leite Pasteurizado e o Regulamento Técnico da Coleta de Leite Cru Refrigerado e seu Transporte a Granel, em conformidade com os Anexos desta Instrução Normativa. Diário Oficial da República Federativa do Brasil, Brasília, 30 dez. 2011. Seção 1, p. 6.

GALVÃO JÚNIOR, J. G. B. et al. Efeito da produção diária e da ordem de parto na composição físicoquímica do leite de vacas de raças zebuínas. Acta Veterinaria Brasilica, v. 4, n. 1, p. 25-30, 2010.

GOMES, T. C. L. Aglomerações Produtivas e Desenvolvimento Local: Arranjos produtivos locais de amêndoa da castanha-de-caju nos municípios de Barreira e Pacajus no Estado do Ceará. 2007. 274f. Tese (Doutorado em Agronegócios) - Universidade Federal do Rio Grande do Sul, Porto Alegre, 2007.

GUERREIRO, P. K. et al. Qualidade microbiológica de leite em função de técnicas profiláticas no manejo de produção. Ciência e Agrotecnologia, v. 29, n. 1, p. 216-222, 2005.

MINAYO, M. C. S. et al. Métodos, técnicas e relações em triangulação In. MINAYO, M. C. S. et al. (orgs). Avaliação por triangulação de métodos: abordagem de programas sociais. Rio de Janeiro: Editora Fiocruz, 2010. p. 71-103.

MORORÓ, A. M. et al. Manejo sanitário da ordenha e qualidade do leite caprino: Estudo de caso de Unidade Produtora no Município de Monteiro - PB. In: CONGRESSO NORDESTINO DE PRODUÇÃO ANIMAL, 6.; SIMPÓSIO NORDESTINO DE ALIMENTAÇÃO DE RUMINANTES, 7.; FÓRUM DE COORDENADORES DE PÓS GRADUAÇÃO EM PRODUÇÃO ANIMAL DO NORDESTE,
1.; FÓRUM DE AGROECOLOGIA RO RIO GRANDE DO NORTE, 1., 2010, Mossoró. Anais... Mossoró: Sociedade Nordestina de Produção Animal; UFERSA, 2010. 4 f. 1 CD-ROM.

QUIVY, R.; CAMPENHOUDT, L. Manual de investigação em ciências sociais. $3^{\mathrm{a}} \mathrm{ed}$. Lisboa: Gradiva, 2003. 34 p.

RANGEL, A. H. N. et al.Correlação entre a contagem de células somáticas (CCS) e o teor de gordura, proteína, lactose e extrato seco desengordurado do leite. Revista Verde de Agroecologia e Desenvolvimento Sustentável, v. 4 , n. 3, p. 57-60. 2009.

SILVA, F. C. N. N. et al. Características de produção de leite cru obtido por ordenha manual em propriedades rurais localizadas no município de São Mateus - ES. Revista do Instituto de Laticínios Cândido Tostes, v. 64, n. 371, p. 21 26, 2009.

SILVA, P. H. C. Qualidade do leite produzido e beneficiado no Distrito Federal (Brasil) quanto à adequação à Instrução Normativa $n^{0}$ 51/2002. 2010. 80 f. Dissertação (Mestrado em Ciências Animais) - Universidade de Brasília, Brasília, 2010.

SILVA, M. C. D. et al. Caracterização microbiológica e físico-química do leite pasteurizado destinado ao Programa do leite no Estado de Alagoas. Ciência e Tecnologia de Alimentos, v. 28, n. 1, p. 226230, 2008.

TAVOLARO, P. et al. Evaluation of the knowledge in hygiene practices: a qualitative approach. Interface - Comunicação, Saúde e Educação, v. 10, n. 19 , p. $243-54,2006$.

VISOTTO, R. G. et al. Queijo Minas Frescal: perfil higiênico-sanitário e avaliação da rotulagem. Revista do Instituto Adolfo Lutz, v. 70, n. 1, p. 8-15, 2011.

ZOCCAL, R. et al. Competitividade da cadeia produtiva do leite no Ceará: produção primária. $1^{a}$ ed. Juiz de Fora: Embrapa Gado de Leite, 2008. $384 \mathrm{p}$. 